\title{
Urinary excretion of histamine and methylhistamine after burns
}

Joakim Johansson, Emmanuel Bäckryd, Göran Granerus and Folke Sjöberg

\section{Linköping University Post Print}

N.B.: When citing this work, cite the original article.

Original Publication:

Joakim Johansson, Emmanuel Bäckryd, Göran Granerus and Folke Sjöberg, Urinary excretion of histamine and methylhistamine after burns, 2012, Burns, (38), 7, 1005-1009.

http://dx.doi.org/10.1016/j.burns.2012.02.014

Copyright: Elsevier

http://www.elsevier.com/

Postprint available at: Linköping University Electronic Press

http://urn.kb.se/resolve?urn=urn:nbn:se:liu:diva-85848 


\section{Urinary excretion of histamine and methylhistamine after}

\section{burns}

Joakim Johansson, MD ${ }^{1,4}$, Emmanuel Bäckryd, MD ${ }^{1,5}$, Göran

Granerus, MD, $\mathrm{PhD}^{2}$, Folke Sjöberg, MD, Prof ${ }^{1,3,4}$

Departments of Anesthesiology and Intensive Care, ${ }^{1}$ Clinical Physiology, ${ }^{2}$ and the Burns Unit, Hand and Plastic Surgery. ${ }^{3}$ Clinical and Experimental Medicine, ${ }^{4}$ Pain and Rehabilitation centre, ${ }^{5}$ Faculty of Health Sciences, Linköping University Hospital and Linköping University, Linköping, Sweden

Address correspondence to:

Joakim Johansson, M.D.

Department of Anesthesiology and Intensive Care,

Östersund Hospital

SE 83183 SWEDEN

Phone: $\quad+4663153000$

Fax: $\quad+4663$

e-mail: $\quad$ joakim.johansson@jll.se

This study was supported by the research and development unit, Jämtland County Council, Sweden. 


\begin{abstract}
Background: The increased vascular permeability seen post burn contribute to morbidity and mortality as it interferers with organ function and the healing process. Large efforts have been made to explore underlying pathophysiological mechanisms that generate increased vascular permeability after burns. Many different substances have been proposed as mediators of which histamine, serotonin and oxygen radicals are claimed most important. However, no specific blocker has convincingly been shown to be clinically effective. Early work has claimed increased histamine plasma-concentrations in humans postburn and data from animal models pointed at histamine as an important mediator. Modern human clinical studies investigating the role of histamine as a mediator of the generalized post burn increase in vascular permeability are lacking.

Method: We examined histamine turnover by measuring the urinary excretion of histamine and methyl histamine for $48 \mathrm{~h}$ after burns in 8 patients (mean Total Burn Surface Area 24\%) Results: Over time, in this time frame and compared to healthy controls we found a small increase in the excretion of histamine, but no increase of its metabolite methylhistamine. Conclusion: Our findings do not support that histamine is an important mediator of the increased systemic vascular permeability seen post burn.
\end{abstract}

Key words: burn, histamine, mediator, oedema, vascular permeability 


\section{Introduction}

Extensive thermal injuries result in a massive inflammatory response that has both local and systemic effects which, if not alleviated, may lead to shock [1-2]. Histamine is one of the classic mediators of inflammation. Mast cells that, together with basophils, store most of the histamine in humans are present in loose connective tissue, particularly around blood vessels. They are abundant in skin, and the dermis contains 3000-12 000 mast cells/ $\mathrm{mm}^{3}$ [3].

Different stimuli, like anaphylatoxins, several interleukins, physical stimuli such as heat and cold, free radicals, and others, can induce stimulation of mast cells which leads to degranulation and histamine release [3-5].

Histamine is thought to be an important mediator of vascular dysfunction in burn wounds, particularly in the early phase $[1,6]$. Previous data have relied mostly on animal studies $[5,7]$, and we know of few consistent newer data in humans [8-10]. Results from animal experiments may not apply to humans for different reasons, particularly the interspecies and intraspecies heterogeneity of different subpopulations of mast cells [11]. Locally-released histamine was investigated in pigs by Papp et al [12], who found increased concentrations locally in burned tissue with microdialysis. Systemic plasma histamine concentrations were moderately increased early, but then returned to the reference range.

In this study we aimed to detect an initial acute release of histamine in humans during the first 48 hours after a minor to moderate burn. The underlying hypothesis was that an increased turnover of histamine during this period will indicate that histamine is an important mediator for the increase in vascular permeability that elicits the formation of edema seen after a burn. As circulating histamine in plasma is rapidly degraded and excreted in the urine, the most 
reliable way to assess histamine turnover in the body quantitatively is to look at urinary concentrations of histamine and its metabolites [13].

\section{Materials and Methods}

The study was conducted in a national burn unit, located at a tertiary referral university hospital in Linköping, Sweden. Eight consecutive patients admitted with a total burn surface area (TBSA \%) of more than $10 \%$ were included. The unit serves a population of 5 million in the south of Sweden. The treatment regimens in the unit include resuscitation according to the Parkland formula and early excision and grafting. Ventilatory assistance, nutritional support, and pain control are given according to a protocol described elsewhere [14]. The regional ethics review board were consulted and agreed that the study could be conducted without an informed consent since the study material was urine samples.

The urinary excretion of histamine and methylhistamine in healthy controls were measured in 24-hour urine samples. To compare their excretion levels with those of the patients, controls were divided by 4 to obtain the excretion/6 hours. This is not entirely correct as histamine excretion (and probably that of methylhistamine) is not constant during the 24 hours of the day (it is lower at night), but the potential error introduced by this procedure is small.

\section{Collection of urine}

On admission, the patient had a catheter inserted and the bladder emptied ("preadmission" urine). The amounts of histamine and methylhistamine in preadmission urine are not directly comparable with those measured in the burn unit or those from the controls, as the sampling time (when the patient's bladder was last emptied before a catheter was inserted) was not 
known. Therefore the amounts of histamine and methylhistamine in these samples were corrected for the creatinine excretion.

The urine produced in the ward was collected every 6 hours for 48 consecutive hours. After collection it was immediately acidified and the volume measured. An aliquot was kept and frozen. The urine samples were analyzed by reversed phase ion-pair high performance liquid chromatography (HPLC) [15-16] at the department of Clinical Physiology, Linköping University Hospital. The amounts excreted were compared with results obtained from a healthy control group $(n=20)$ [17]. The urinary excretion of creatinine was also measured in each patient sample. Histamine and methylhistamine were then corrected for creatinine excretion (expressed as $\mu \mathrm{mol} / \mathrm{mol}$ creatinine).

\section{Data analysis and statistics}

Data are presented as mean and 95\% confidence interval (CI). Differences between controls and the first urinary fraction were assessed by the Mann-Whitney U test. Changes in histamine and methylhistamine excretion over time were examined by the Friedman test. To aid with statistical analysis we used Statistica 10 (StatSoft).

\section{Results}

\section{Details of patients (Table I)}

The median total burn surface area (TBSA \%) was 24\% (range 11\%-37\%) with no mortality (Table I). 


\section{Histamine and methylhistamine excretion}

The urinary excretion of histamine/6 hours is shown in Figure 1. There was a significant difference between controls and the first urinary fraction ( $0-6$ hours) of patients $(\mathrm{p}=0.0021)$

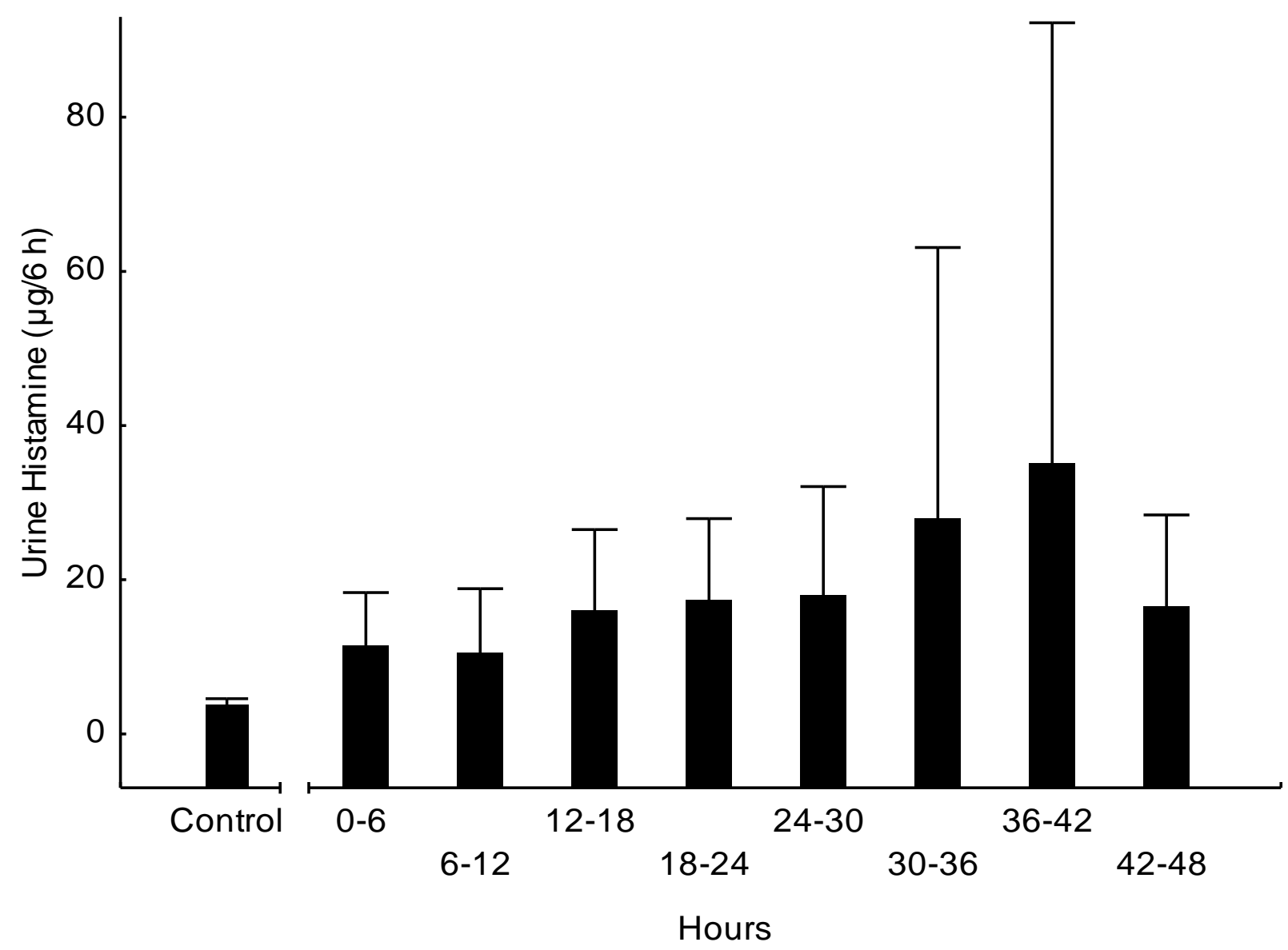

Figure 1: Urine levels of Histamine per 6 hours. Mean and CI (95\%) in the 8 patients compared to 20 healthy controls.

The urinary excretion/6 hours of methylhistamine is shown in Figure 2. There was no difference between controls and the patients first urinary fraction $(0-6$ hours $)(p=0.98)$. 


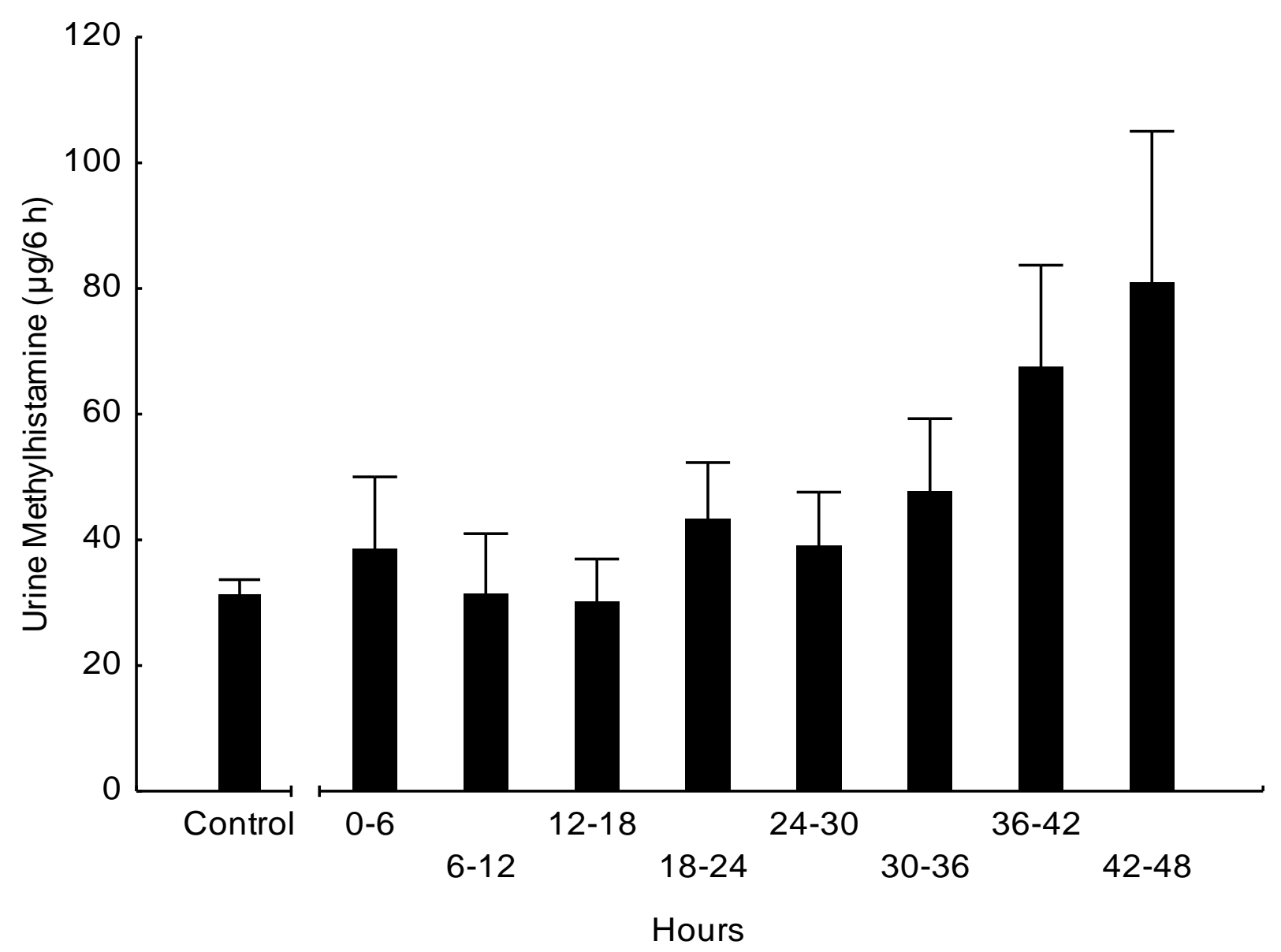

Figure 2: Urine levels of Methylhistamine per 6 hours. Mean and CI (95\%) in the 8 patients compared to 20 healthy controls.

There were no significant changes over time in the excretion of either histamine or methylhistamine. There were, however, variations in transport time to the burn unit (Table 1). To allow for this we assigned the first urine sample from case 1 to be 12-18 hours after the burn and the first sample from cases 3 and 7 to be 6-12 hours after the burn instead of 0-6 hours before we applied the Friedman test.

In case1, who had the highest excretion of both histamine and methylhistamine, the excretion of methylimidazoleacetic acid (the main metabolite of histamine) was also measured, and was found to be within the normal range (data not shown). 


\section{Histamine and methylhistamine excretion corrected for creatinine excretion}

The histamine and methylhistamine excretions corrected for creatinine excretion are shown in

Figures 3 and 4, respectively. We found no significant changes during the time period studied. The excretion of histamine and methylhistamine in the preadmission urine did not differ from that in the following fractions when they were corrected for creatinine excretion.

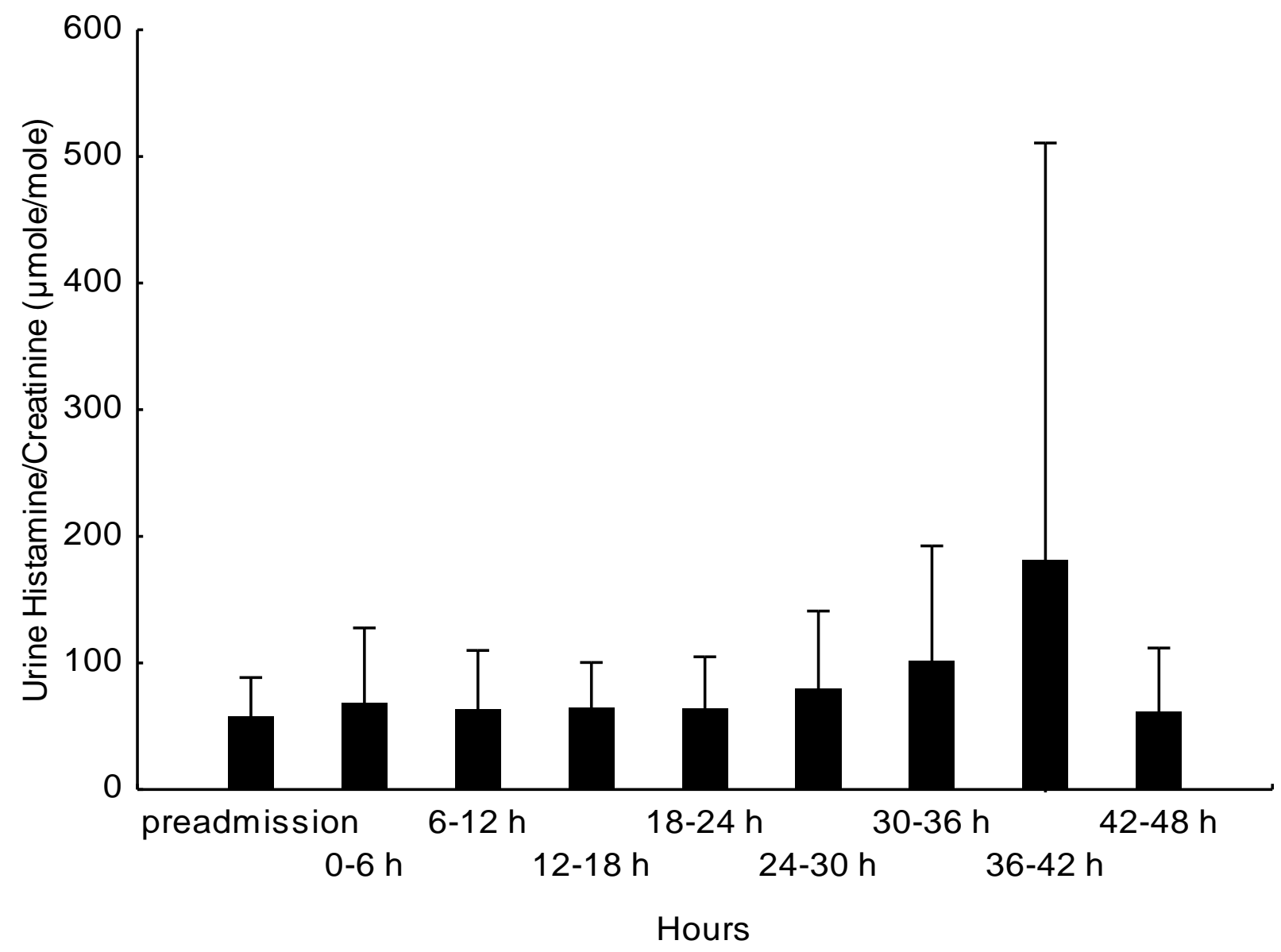

Figure 3: Urine levels of Histamine divided by the corresponding creatinine per 6 hours. Mean and CI (95\%).

\section{Discussion}

Interest in the role of histamine in burns has a long history. In 1936, Barsoum and Gaddum reported high and rising concentrations of histamine in blood for days after a major burn [10]. Since then, it has been thought to have an important role in the pathophysiology of burns, 
particularly in the early phase of edema after a burn [1]. We know now that concentrations of histamine in blood are in the range of 100 times greater than those in plasma, and are related to the number of basophils. If histamine is supposed to cause systemic effects one would expect an increase in plasma levels of histamine early after the burn. In Animal experimental models it has been shown that histamine is released into plasma after a burn [7, 18], so it is reasonable to hypothesize that it may also be released from human burned skin and may play a part in systemic, burn-induced, vascular dysfunction. Clinically, immediate plasmasampling in relation to the injury is not available, and urine analyses are the only tests we have. However, histamine is rapidly cleared from plasma and excreted by the kidneys, and the urinary output will be a sensitive indicator of histamine release [13].

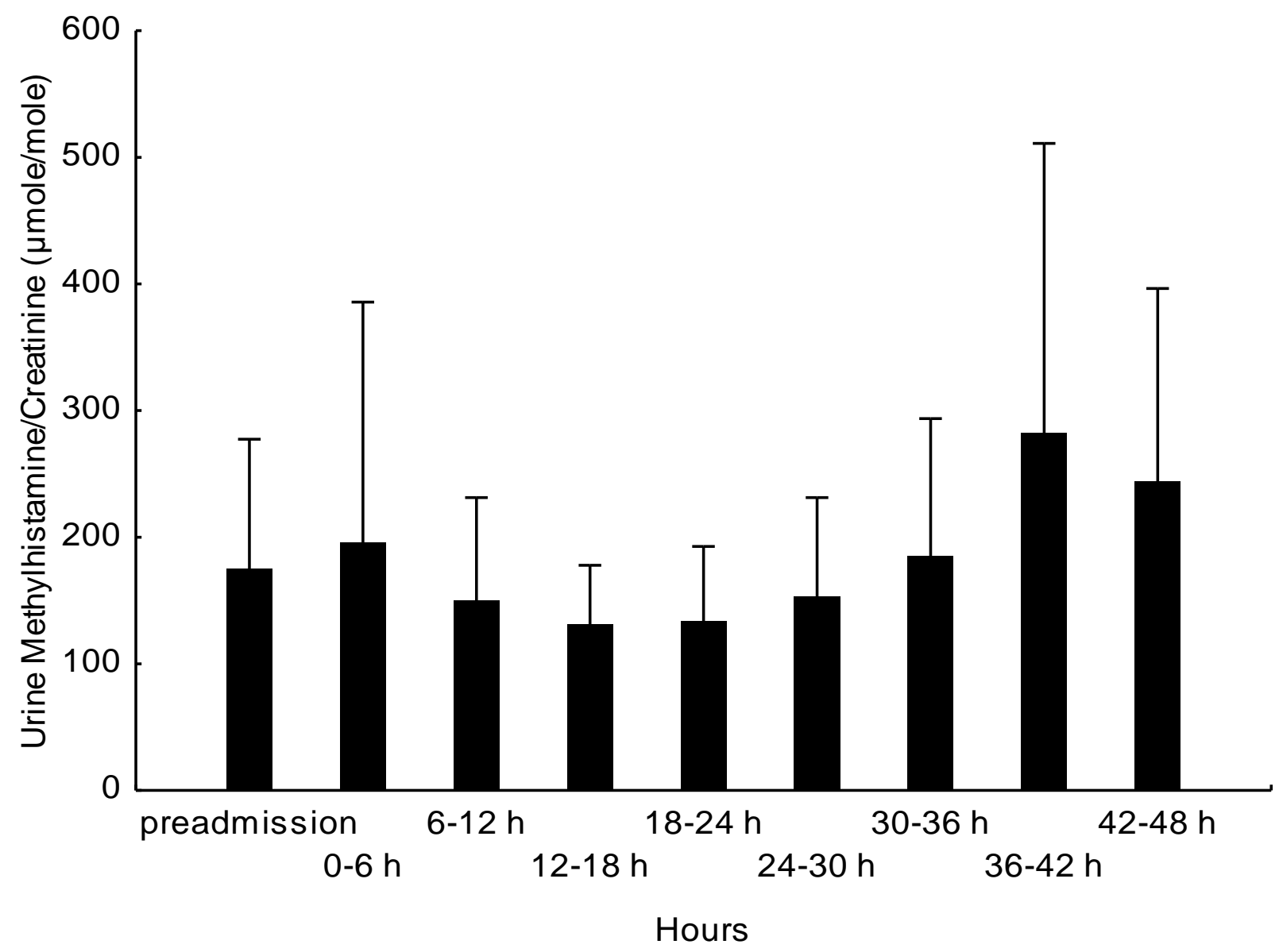

Figure 4: Urine levels of Methylhistamine divided by the corresponding creatinine per 6 hours. Mean and CI (95\%). 
In 1957, Birke et al reported high urinary excretions of histamine in humans [9], whereas Agrup et al failed to confirm an increase in histamine turnover as measured by urinary excretion of its metabolites [8]. Results from giving antihistamines systemically after a burn are also contradictory. While the $\mathrm{H}_{2}$-antagonist cimetidine reduced edema after a burn in animals [18-20], another $\mathrm{H}_{2}$-antagonist (ranitidine) did not [21].

Conclusive evidence for an appreciable release of histamine from human skin after a burn is therefore scarce at best. We evaluated histamine release for 48 hours in 8 burned patients by measuring the excretion of histamine and histamine metabolites (methylhistamine, and in one case methylimidazoleacetic acid) in the urine. As Agrup et al [8] measured excretion only in 24-hour periods, we thought that a possible early and short-lasting release of histamine could have been missed, and so we decided to collect urine every 6 hours, as well as the preadmission urine. The kidneys effectively remove histamine from plasma, the renal extraction ratio being roughly $80 \%[13,22]$, and most tissues (including the kidneys) have a good capacity to metabolize histamine so that only a small amount of circulating free histamine is excreted unchanged in the urine [13, 17, 23-24]. To be able to evaluate the histamine turnover rate fully, therefore, it is crucial to measure concentrations of histamine metabolites as well as those of histamine. We found a slight increase in histamine excretion during the first 48 hours after admission, but values for histamine metabolites were within the normal ranges - that is, in agreement with the results of Agrup et al [8]. A solitary increase in histamine excretion in the urine may reflect increased histamine production by the kidney itself rather than a systemic release. Some studies have suggested that the main source of urinary histamine may be de novo synthesis in the kidney [25], and this might be of greater importance if the histamine precursor histidine is present in larger concentrations. Aminoaciduria roughly proportional to the severity of the burn has been reported in burned patients [26-27]. Consequently, as histamine may be produced by the kidney, detecting an 
increase in histamine excretion only would not prove that there was also an increase in plasma. A parallel increase in histamine and methylhistamine would be a much stronger indication of a systemic release [28].

Burn care involves an early massive resuscitation, often according to the Parkland formula. This in combination with the increase in vascular permeability results in an early increase in total body water. The kidneys will strive to restore normal fluid balance and an increased urine production is seen from 24-(48) hours after the burn and further. This alteration may affect the dynamics of excreted histamine and metylhistamine and are compensated for by looking instead at the excretion in relation to creatinine. When we did this creatininecorrection we could still not see alterations in excretion during the study.

The systemic change in vascular permeability sets in early after a burn, and is maintained during the first 24-48 hours [29]. We therefore suspected that a mediator of systemicallyincreased permeability would be detected early, and within 48 hours it would also decrease to the normal range or close to it. This was not the case in the present study for histamine and methylhistamine, and we think that the role of histamine as a mediator of systemic increased vascular permeability has been somewhat exaggerated by previous publications.

Although our study is hampered by the small number of patients $(n=8)$ and the fact that most burns were minor to moderate (mean TBSA \% 24), we believe that further studies are needed to determine if histamine, as stated by relevant literature, really is an important mediator of vascular permeability increase after burns. This study did not look at the possible local effect of histamine in burned skin. 
In conclusion we have shown a slight increase in urinary histamine excretion 0-48 hours after a moderate to major burn, which is not paralleled by an increase in the excretion of histamine metabolites. In contrast to our hypothesis, our findings do not support that histamine is an important mediator of systemic vascular dysfunction after burns.

\section{Conflict of interest statement}

None of the authors have declared any conflicts of interest. 


\section{References}

[1] Kramer GC, Lund T and Orlando KB. Pathophysiology of burn shock and burn edema. In: Herndon DN, Editor. Total burn care, Philadelphia: Saunders; 2007, p. 93 106

[2] Gibran NS and Heimbach DM. Mediators in thermal injury. Semin Nephrol 1993; 13(4): $344-58$.

[3] Atkinson TP, White MV and Kaliner MA. Histamine and Serotonin. In: Gallin JI, Goldstein IM and Snyderman R, Editors. Inflammation: Basic Principles and Clinical Correlates, New York: Raven Press, Ltd; 1992, p. 193-209

[4] Kubes P and Granger DN. Leukocyte-endothelial cell interactions evoked by mast cells. Cardiovasc Res 1996; 32(4): 699-708.

[5] Metcalfe DD, Baram D and Mekori YA. Mast cells. Physiol Rev 1997; 77(4): 103379.

[6] Arturson G. Pathophysiology of the burn wound and pharmacological treatment. The Rudi Hermans Lecture, 1995. Burns 1996; 22(4): 255-74.

[7] Yurt RW and Pruitt BA, Jr. Base-line and postthermal injury plasma histamine in rats. J Appl Physiol 1986; 60(5): 1782-8.

[8] Agrup P, Graneurs G, Jacobsson S, Wetterqvist H and White T. Histamine metabolism in burn injuries. Scand J Plast Reconstr Surg 1974; 8(3): 198-201.

[9] Birke G, Duner H, Liljedahl S-O, Pernow B, Plantin L-O, Troell L. Histamine, catecholamines and adrenocortical steroids in burns. Acta Chir Scand 1957; 114: 8798.

[10] Barsoum G and Gaddum J. The effect of cutaneous burns on the blood - histamine. Clinical Science 1936; 2: 357-62. 
[11] Church MK, el-Lati S and Okayama Y. Biological properties of human skin mast cells. Clin Exp Allergy 1991; 21 Suppl 3: 1-9.

[12] Papp A, Harma M, Harvima R, Lahtinen T, Uusaro A and Alhava E. Microdialysis for detection of dynamic changes in tissue histamine levels in experimental thermal injury. Burns 2005; 31(4): 476-81.

[13] Helander CG, Lindell SE and Westling H. The renal removal of C-14-labelled histamine from the blood in man. Scand J Clin Lab Invest 1965; 17(6): 524-8.

[14] Sjoberg F, Danielsson P, Andersson L, Steinwall I, Zdolsek J, Ostrup L, et al. Utility of an intervention scoring system in documenting effects of changes in burn treatment. Burns 2000; 26(6): 553-9.

[15] Granerus G. Current Techniques of Histamine Determination: Determination by HighPerformance Liquid Chromatography. In: Uvnäs B, Editor. Handbook of Experimental Pharmacology, Vol. 97: Springer-Verlag; 1991, p. 49-57

[16] Granerus G and Wass U. Urinary excretion of histamine, methylhistamine (1-MeHi) and methylimidazoleacetic acid (MeImAA) in mastocytosis: comparison of new HPLC methods with other present methods. Agents Actions 1984; 14(3-4): 341-5.

[17] Granerus G. Urinary excretion of histamine, methylhistamine and methylimidazoleacetic acids in man under standardized dietary conditions. Scand J Clin Lab Invest Suppl 1968; 104: 59-68.

[18] Friedl HP, Till GO, Trentz O and Ward PA. Roles of histamine, complement and xanthine oxidase in thermal injury of skin. Am J Pathol 1989; 135(1): 203-17.

[19] Boykin JV, Jr., Eriksson E, Sholley MM and Pittman RN. Histamine-mediated delayed permeability response after scald burn inhibited by cimetidine or cold-water treatment. Science 1980; 209(4458): 815-7. 
[20] Tanaka H, Wada T, Simazaki S, Hanumadass M, Reyes HM and Matsuda T. Effects of cimetidine on fluid requirement during resuscitation of third-degree burns. J Burn Care Rehabil 1991; 12(5): 425-9.

[21] Boykin JV, Jr and Manson NH. Mechanisms of cimetidine protection following thermal injury. Am J Med 1987; 83(6A): 76-81.

[22] Lindell SE and Schayer RW. The renal removal of injected [14C] histamine from the blood in dogs. Br J Pharmacol Chemother 1958; 13(1): 44-51.

[23] Kaliner M, Shelhamer JH and Ottesen EA. Effects of infused histamine: correlation of plasma histamine levels and symptoms. J Allergy Clin Immunol 1982; 69(3): 283-9.

[24] Cooper JA and Schayer RW. Metabolism of C14 histamine in man. J Appl Physiol 1956; 9(3): 481-3.

[25] Abboud HE and Dousa TP. Renal metabolism and actions of histamine and serotonin. Miner Electrolyte Metab 1983; 9(4-6): 246-59.

[26] Eades CH, Jr., Pollack RL and Hardy JD. Thermal burns in man. IX. Urinary amino acid patterns. J Clin Invest 1955; 34(12): 1756-9.

[27] Nardi GL. Essential and nonessential amino acids in the urine of severely burned patients. J Clin Invest 1954; 33(6): 847-54.

[28] Granerus G, Wetterqvist $\mathrm{H}$ and White T. Histmaine metabolism in healthy subjects before and during treatment with aminoguanidine. Scand J Clin Lab Invest Suppl 1968; 104: 39-48

[29] Steinvall I, Bak Z and Sjoberg F. Acute respiratory distress syndrome is as important as inhalation injury for the development of respiratory dysfunction in major burns. Burns 2008; 34(4): 441-51. 
Table 1. Details of patients.

\begin{tabular}{ccccc}
\hline Case No & Sex & $\begin{array}{l}\text { Age } \\
\text { (years) }\end{array}$ & TBSA \% & $\begin{array}{l}\text { Transport time } \\
\text { (hours) }\end{array}$ \\
\hline & & & & 20 \\
1 & M & 43 & 30 & $*$ \\
2 & M & 50 & 11 & 13 \\
3 & M & 44 & 23 & 3,5 \\
4 & $\mathrm{~F}$ & 13 & 32 & 8 \\
5 & $\mathrm{M}$ & 89 & 14 & 5 \\
6 & $\mathrm{~F}$ & 52 & 24 & 10 \\
7 & $\mathrm{M}$ & 9 & 37 & 4 \\
8 & $\mathrm{~F}$ & 75 & 17 & \\
\hline
\end{tabular}

* Data missing.

TBSA $\%=$ total burn surface area $(\%)$. 